\title{
BURNOUT DENGAN SELF EFFICACY PADA PERAWAT
}

\author{
Trivena Larengkeng \\ Lenny Gannika \\ Rina Kundre
}

\author{
Program Studi Ilmu Keperawatan Fakultas Kedokteran \\ Universitas Sam Ratulangi \\ Email : venalarengkeng@yahoo.com
}

\begin{abstract}
Nurses have a big responsibility because nurses are human service occupation that give a service to the society. Being a nurse had many job demands that potentially can be a stressor (burnout). Nurses must have disposition of certain behavior to finish it. One of disposition behavior is self efficacy. The purpose of this research is to know the Corelation between burnout and self efficacy of nurses at medical ward RSU GMIM Pancaran Kasih Manado. Design of this research used Descriptive Analytic With Cross Sectional Study approach. The sample was 61 respondent, used non random samplimg technique. The result of statistic test that used Chi-Square test in significance level was $95 \%$, and significant score $p$ vzlue $=0,020<\alpha(0,05)$. Conclusion that there is a corelation between burnout and self efficacy of nurses in medical ward.
\end{abstract}

Keywords : Burnout, Self Efiicacy, Nurses

\begin{abstract}
Abstrak: Perawat memiliki tanggung jawab yang tinggi karena memiliki pekerjaan yang bersifat human service atau memberikan pelayanan kepada masyarakat, Tanggung jawab dan tuntutan pekerjaan yang banyak dapat berpotensi menjadi stressor (burnout) bagi perawat Perawat dituntut untuk memiliki disposisi perilaku tertentu agar dapat menyelesaikannya. Salah satu disposisi perilaku tersebut ialah efikasi diri (Self efficacy). Tujuan untuk mengetahui hubungan Burnout dengan self efficacy pada perawat di ruang rawat inap RSU Gmim Pancaran Kasih Manado. Desain penelitian yang digunakan yaitu Deskriptif Analitik dengan pendekatan Cross Sectional Study. Sampel berjumlah 61 responden yang didapat dengan menggunakan tehnik non random sampling. Hasil penelitian uji statistik menggunakan uji Chi-square pada tingkat kemaknaan 95\%, didapatkan nilai signifikan $\rho$ Value $=0,020<\alpha(0,05)$. Kesimpulan ada hubungan antara burnout dengan self efficacy pada perawat di ruang rawat inap.
\end{abstract}

Kata Kunci : Burnout, Self Efficacy, Perawat

\section{PENDAHULUAN}

Perawat memiliki tanggung jawab yang tinggi karena memiliki pekerjaan yang bersifat human service atau memberikan pelayanan kepada masyarakat yang dituntut untuk memiliki keterampilan yang baik dalam bidang kesehatan (Perry \& Potter, 2005). Tanggung jawab dan tuntutan pekerjaan yang banyak dapat berpotensi menjadi stresor bagi perawat. Stresor yang terjadi secara terus menerus dan tidak mampu diadaptasi oleh individu akan menimbulkan beberapa gejala yang disebut dengan burnout syndrome. Burnout syndrome merupakan suatu kumpulan gejala fisik, psikologis dan mental yang bersifat destruktif akibat dari kelelahan kerja yang bersifat monoton dan menekan. Burnout syndrome banyak ditemukan pada profesi yang bersifat human service seperti polisi, perawat, dokter, konselor, dan pekerja sosial. (Pangastiti, 2011).

Al-Turki, et al (2010) melakukan penelitian terkait burnout syndrome pada perawat yang berjudul "Burnout Syndrome among Multinational Nurses Working in Saudi Arabia" menunjukkan hasil 89\% staf perawat mengalami emotional 
exhaustion, $\quad 42 \% \quad$ mengalami depersonalization, dan $71,5 \%$ mengalami lowpersonal accomplishment.

Dimensi burnout terdiri dari 3 hal yaitu kelelahan emosi, perubahan kepribadian dan pencapaian pribadi yang rendah. Burnout sudah menjadi perhatian global dan berhubungan dengan stres yang berhubungan dengan pekerjaan, berpotensi negatif terhadap kesehatan fisik dan psikologis individu serta berdampak pada efektifitas suatu organisasi.(Huber, 2006). Burnout yang terjadi karena stress kerja yang berkepanjangan merupakan suatu keadaan yang tidak dapat dihindari oleh perawat dalam menjalankan tugasnya (Dora, 2014).

Perawat dituntut untuk memiliki disposisi perilaku tertentu agar dapat menyelesaikannya. Salah satu disposisi perilaku tersebut ialah efikasi diri (Self efficacy). Self efficacy diartikan sebagai suatu keyakinan tentang kemampuan untuk dapat menyelesaikan pekerjaan dengan berhasil. Self efficacy mengacu pada keyakinan individu mengenai kemampuannya memobilisasi motivasi, sumber daya kognitif dan tindakan yang diperlukan agar berhasil melaksanakan tugas dalam konteks tertentu. Self efficacy yang tinggi akan mengembangkan kepribadian yang kuat pada seseorang, mengurangi stres dan tidak mudah terpengaruh oleh situasi yang mengancam.

Individu dengan self efficacy rendah akan cenderung tidak mau berusaha atau tidak menyukai pekerjaan sama dalam situasi yang sulit dan tingkat kompleksitas yang tinggi. Self efficacy juga membantu menentukan berapa banyak upaya yang akan dikeluarkan orang untuk suatu kegiatan, berapa lama mereka akan bertahan ketika menghadap hambatan, dan seberapa tangguh mereka dalam menghadapi situasi yang buruk. (Pajeres, 2002). Self efficacy adalah suatu keyakinan individu bahwa dirinya mampu untuk melakukan sesuatu dalam situasi tertentu dengan berhasil. Hal ini akan mengakibatkan bagaimana individu merasa, berfikir dan bertingkah-laku (keputusan-keputusan yang dipilih, usahausaha dan keteguhannya pada saat menghadapi hambatan), memiliki rasa bahwa individu mampu untuk mengendalikan lingkungan (sosial)nya (Pajeres, 2002).

Individu yang memiliki self efficacy tinggi, pada saat menghadapi situasi yang menekan akan berusaha lebih keras dan bertahan lama serta akan lebih aktif dalam berusaha daripada orang yang mempunyai self eficacy rendah, dan akan lebih berani menetapkan target atau tujuan yang akan dicapai. Orang yang memiliki self efficacy tinggi akan berusaha melakukan tugas atau tindakan untuk mencapai tujuan yang telah ditentukan dan berusaha beradaptasi dengan berbagai rintangan-rintangan dalam pekerjaan mereka termasuk burnout yang dialaminya. Begitu juga seorang perawat yang memiliki self efficacy tinggi akan mampu mengatasi burnout yang dialaminya karena adanya tuntutan tuntutan dalam pekerjaan mereka. Seorang perawat yang memiliki self efficacy tinggi akan memiliki tingkat burnout yang rendah (Sulistyowati, 2007).

Berdasarkan hasil pengamatan yang dilakukan peneliti di RSU GMIM Pancaran Kasih Manado didapatkan bahwa beberapa perawat di ruang rawat inap memiliki gejala-gejala burnout seperti terlihat lesu, kurang bersemangat, keluhan pegal dan rasa lelah. Berdasarkan hasil pengisian kuisioner sebagian perawat mengalami kelelahan, gangguan pola tidur dan sakit kepala, beberapa perawat juga yakin dan bersemangat dalam menjalankan tugas dan pekerjaannya. Berdasarkan latar belakang penelitian diatas maka peneliti tertarik untuk melakukan penelitian mengenai "Hubungan Burnout dengan Self Efficacy pada Perawat Ruang Rawat Inap di RSU GMIM Pancaran Kasih Manado" 


\section{METODE PENELITIAN}

Penelitian ini termasuk dalam jenis penelitian kuantitatif dengan menganalisis gambaran hubungan antara kedua variabel yaitu variabel independen (Burnout) dan variabel dependen (Self Efficacy). Penelitian ini menggunakan desain penelitian cross sectional. Penelitian ini dilaksanakan di RSU Gmim Pancaran Kasih Manado pada bulan Juni 2019. Populasi penelitian ini merupakan seluruh Perawat ruang rawat inap jumlah 158. Pengambilan sampel menggunakan teknik non random sampling dengan metode purposive sampling dengan rumus slovin maka didapatkan jumlah sampel 61 Perawat. Instrumen penelitian yang digunakan untuk mengukur variabel Burnout menggunakan kuesioner, Kuesioner ini terdiri dari 40 pernyataan. $1=$ sangat tidak setuju, $2=$ tidak setuju, 3= setuju , 4= sangat setuju untuk pernyataan positif dan untuk pernyataan negatif $\mathrm{SS}=$ $1, \mathrm{~S}=2$, TS $=3$, dan $\mathrm{STS}=4$. Setelah lembar kuesioner diisi oleh responden, kemudian dilakukan penghitungan skor dengan cara menjumlahkan skor tiap pertanyaan. Untuk menentukan tingkat Burnout perawat dilihat dari skor tertinggi. Pengukuran Self Efficacy menggunakan kuesioner dengan kriteria skor $\mathrm{SS}=4, \mathrm{~S}=$ 3 , TS 2, STS $=1$.

Pengolahan data yang diperoleh dari hasil penelitian ini diolah secara manual dengan mengelompokkan hasil wawancara dan observasi kemudian dilakukan penghitungan skor dan dianalisis menggunakan uji statistik melalui sistem komuterisasi dengan beberapa tahap yaitu editing, coding, cleaning, tabulating (Notoatmodjo, 2010). Analisa bivariat dalam penelitian ini yaitu untuk mengetahui hubungan Burnout dan self efficacy pada perawat di ruang rawat inap RSU Gmim Pancaran Kasih Manado. Peneliti menggunakan uji statistic Chi Square dengan tingkat kemaknaan 95\% ( $\alpha$ $=0,05$ ).
HASIL dan PEMBAHASAN

1. Karakteristik Responden

Tabel 1. Distribusi Responden

Berdasarkan Jenis Kelamin

\begin{tabular}{ccc}
\hline $\begin{array}{c}\text { Jenis } \\
\text { Kelamin }\end{array}$ & n & \% \\
\hline Laki-Laki & 10 & 16,4 \\
\hline Perempuan & 51 & 83,6 \\
\hline Total & $\mathbf{6 1}$ & $\mathbf{1 0 0 , 0}$ \\
\hline
\end{tabular}

Sumber : Data Primer 2019

Hasil penelitian pada 61 responden didapatkan mayoritas responden berjenis kelamin perempuan yaitu sebanyak 51 responden $(83,6 \%)$, sedangkan laki-laki sebanyak 10 responden (16,4\%). Perawat merupakan salah satu profesi dimana jenis kelamin perempuan merupakan mayoritas, baik di rumah sakit, puskesmas maupun pelayanan kesehatan lainnya. Hal ini sudah terlihat dari sejak calon perawat melaksanakan pendidikan di istitusi pendidikan, dimana mahasiswa perempuan lebih banyak dari pada mahasiswa laki-laki (Srihandayani, 2016).

Tabel 2. Distribusi Responden Berdasarkan Usia

\begin{tabular}{ccc}
\hline Usia & $\mathbf{n}$ & $\mathbf{\%}$ \\
\hline $20-30$ & 43 & 70,5 \\
tahun & & \\
$31-40$ & 10 & 16,4 \\
tahun & &
\end{tabular}

\begin{tabular}{ccc}
\hline$>40$ Tahun & 8 & 13,1 \\
\hline Total & $\mathbf{6 1}$ & $\mathbf{1 0 0 , 0}$
\end{tabular}

Sumber : Data Primer 2019

Penelitian yang dilakukan pada 61 responden didapatkan mayoritas responden dengan usia 20-30 tahun sebanyak 43 orang (70,5\%), dan yang berusia 31-40 tahun sebanyak 10 orang $(16,4 \%)$ dan usia $>40$ tahun sebanyak 8 orang $(13,1 \%)$. Usia responden tergolong usia spesifikasi sehingga beberapa faktor yang berperan dalam perkembangan self efficacy dan burnout dari seseorang adalah usia. 
Menurut Juniartha \& Candra (2013), terdapat hubungan antara usia dengan self efficacy dan burnout di mana semakin bertambah usia seseorang, cenderung memiliki self efficacy yang tinggi dan burnout yang tinggi juga.

Tabel 3. Distribusi Responden Berdasarkan Tingkat Pendidikan

$\begin{array}{lll}\text { Tingkat } & \mathbf{n} & \%\end{array}$

Pendidikan

\begin{tabular}{ccc}
\hline D3 & 50 & 82,0 \\
\hline S1 Ners & 11 & 18,0 \\
\hline Total & $\mathbf{6 1}$ & $\mathbf{1 0 0 , 0}$ \\
\hline
\end{tabular}

Sumber : Data Primer 2019

Berdasarkan hasil penelitian yang dilakukan pada responden 61 orang, mayoritas responden dengan pendidikan D3 yaitu sebanyak 50 orang $(82,0 \%)$ dan dan S1 Ners sebanyak 11 orang $(18,0)$. Perawat dengan tingkat pendidikan lebih tinggi, mempunyai pertimbangan yang lebih matang di karenakan wawasan yang lebih luas. Hal ini di dukung pula oleh Srihandayani (2016) yang membuktikan bahwa perawat dengan pendidikan D3 Keperawatan dan tingkat pendidikan yang lebih tinggi mempunya efisiensi kerja dan penampilan kerja yang lebih baik (Srihandayani, 2016).

Tabel 4. Distribusi Responden Berdasarkan Lama bekerja

\begin{tabular}{ccc}
\hline $\begin{array}{c}\text { Lama } \\
\text { Bekerja }\end{array}$ & $\mathbf{n}$ & \% \\
\hline 1-5 Tahun & 43 & 70,5 \\
6-10 Tahun & 7 & 11,5 \\
11-15 Tahun & 4 & 6,6 \\
16-20 Tahun & 2 & 3,3 \\
$>$ 20 Tahun & 5 & 8,2 \\
\hline Total & $\mathbf{6 1}$ & $\mathbf{1 0 0 , 0}$
\end{tabular}

Sumber : Data Primer 2019
Hasil penelitian menunjukan bahwa dari 61 Perawat mayoritas memiliki kategori lama bekerja 1-5 tahun sebanyak 43 responden (70,5 \%), 6-10 tahun sebanyak 7 responden $(11,5 \%),>20$ tahun sebanyak 5 responden (8,2\%), 11-15 tahun sebanyak 4 responden $(6,6 \%), 16-20$ tahun sebanyak 2 responden (3,3\%). Makin lama seorang bekerja, maka keterampilan dan pengalamannya juga semakin meningkat (Robbins \& Judge, 2008). Pengalaman merupakan salah satu cara kepemilikan pengetahuan yang di alami seseorang dalam kurun waktu yang tidak di tentukan. Perawat yang memiliki masa kerja lebih lama tentunya mempunyai pengalaman yang lebih banyak. Pengalaman ini dapat berguna ketika perawat menghadapi masalah terkait dengan pasien atau masalah internal dalam dunia keperawatan (Susanti, 2013).

\section{Analisa Univariat}

Tabel 5. Distribusi Responden Berdasarkan Burnout

\begin{tabular}{ccc}
\hline Burnout & $\mathbf{n}$ & $\mathbf{\%}$ \\
\hline Rendah & 10 & 16,4 \\
Tinggi & 51 & 83,6 \\
\hline Total & $\mathbf{6 1}$ & $\mathbf{1 0 0 , 0}$
\end{tabular}

Sumber : Data Primer 2019

Hasil penelitian menunjukan bahwa dari 61 Perawat mayoritas sebanyak 51 orang $(83,6 \%)$ yang memiliki tingkat burnout yang tinggi dan 10 orang $(16,4 \%)$ memiliki tingkat burnout rendah. Burnout yang terjadi pada perawat di Ruang Rawat Inap Gmim Pancaran Kasih Manado juga dapat terjadi karena faktor tidak efektifnya perputaran kerja (rotasi kerja). Menurut (Simamora, 2008), rotasi kerja bertujuan untuk menempatkan perawat pada tempat yang tepat agar perawat memperoleh suasana baru dan kepuasan kerja setinggi mungkin serta dapat menunjukkan prestasi yang lebih tinggi. Dari data yang diperoleh dalam penelitian, hampir sebagian besar perawat yang bekerja di 
ruang rawat inap mengaku sudah lama tidak mengalami pertukaran tempat (rotasi kerja) dengan perawat lainnya. Hal ini tentu saja menimbulkan kebosanan karena setiap hari perawat tersebut harus menghadapi ruang kerja yang sama dan pekerjaan yang sama.

Tabel 6. Distribusi Responden Berdasarkan Self Efficacy

\begin{tabular}{ccc}
\hline Self Efficacy & $\mathbf{n}$ & $\%$ \\
\hline Rendah & 8 & 13,1 \\
Tinggi & 53 & 86,9 \\
\hline Total & $\mathbf{6 1}$ & $\mathbf{1 0 0 , 0}$
\end{tabular}

Sumber : Data Primer 2019

Hasil penelitian menunjukan bahwa dari 61 Perawat mayoritas sebanyak 53 orang $(86,9 \%)$ yang memiliki tingkat self efficacy yang tinggi dan 8 orang $(13,1 \%)$ memiliki tingkat self efficacy yang rendah. Hal ini membuktikan bahwa tingkat self efficacy pada perawat yang ada di ruang rawat inap RSU GMIM Pancaran Kasih Manado sangat tinggi. Dalam penelitian ini, responden memiliki self efficacy yang tinggi di karenakan banyak responden menjawab yakin dapat memberikan pelayanan yang optimal kepada pasien juga mereka merasa yakin dapat menciptakan lingkungan yang nyaman bagi pasien, dan pada penelitian ini responden kebanyakan memiliki pengalaman kerja lebih dari 1 tahun dan memiliki tingkat pendidikan D3 Keperawatan, hal ini dapat menjadi factor self efficacy pada perawat menjadi tinggi.

Self efficacy perawat terbentuk melalui proses belajar sosial yang dapat terjadi pada rumah sakit. Self efficacy terbentuk sebagai proses adaptasi dan pembelajaran yang ada dalam tempat tersebut (Ferianto, dkk, 2016). Semakin lama seseorang bekerja maka semakin tinggi self efficacy yang dimilikinya dalam bidang pekerjaan tertentu. Self efficacy yang tinggi membantu individu untuk menyelesaikan tugas dan mengurangi beban kerja secara psikologis maupun fisik.

\section{Analisa Bivariat}

Tabel 7. Hubungan Burnout dengan Self Efficacy Perawat

\begin{tabular}{|c|c|c|c|c|c|c|c|}
\hline \multirow[t]{3}{*}{ Burnout } & \multicolumn{4}{|c|}{ Self Efficacy } & \multirow{2}{*}{\multicolumn{2}{|c|}{ Total }} & \multirow{3}{*}{ Pv } \\
\hline & \multicolumn{2}{|c|}{ Rendah } & \multicolumn{2}{|c|}{ Tinggi } & & & \\
\hline & n & $\%$ & $\mathbf{n}$ & $\%$ & $\mathbf{n}$ & $\%$ & \\
\hline Rendah & 4 & 40,0 & 6 & 60,0 & 10 & 100 & \\
\hline Tinggi & 4 & 7,8 & 47 & 92,2 & 51 & 100 & 0,020 \\
\hline Total & 8 & 13,1 & 53 & 86,9 & 61 & 100 & \\
\hline$u m l$ & & & & 201 & & & \\
\hline
\end{tabular}

Berdasarkan hasil penelitian yang diperoleh menggunakan uji Fisher's Exact test didapat koefisien korelasi bernilai negatif dengan tingkat signifikan $\rho$ sebesar 0,020 . Artinya terdapat hubungan yang signifikan antara burnout dengan self efficacy pada perawat di ruang rawat inap RSU GMIM Pancaran Kasih Manado. Hal ini dibuktikan dengan hasil mayoritas responden memiliki nilai burnout dan self efficacy yang tinggi. Penelitian sebelumnya menunjukan bahwa self efficacy memiliki hubungan yang signifikan dengan burnout. Hal ini berarti self efficacy memiliki peran terhadap tinggi rendahnya burnout. Semakin tinggi self efficacy maka semakin rendah burnout yang di alaminya (Pamungkas, 2018). Hasil penelitian ini mengatakan hal yang berbeda dimana burnout yang tinggi tidak mempengaruhi self efficacy seorang perawat, sehingga self efficacynya tetap tinggi. Hasil tersebut dapat menggambarkan bahwa dalam menjalani pekerjaan sebagai perawat di rumah sakit, sebagian besar dipengaruhi oleh faktor self efficacy dalam diri perawat itu sendiri.

Penelitian ini di dapatkan responden yang memiliki burnout rendah tetapi self efficacynya tinggi sebanyak 6 orang $(60,0 \%)$, hal ini dapat dikatakan secara umum tingkat burnout yang dialami subjek cenderung rendah. Kondisi ini berhubungan dengan self efficacy subjek yang tinggi. Kemampuan 
untuk menghadapi stres kerja atau burnout berkaitan dengan kenyakinan akan kemampuannya untuk dapat mengontrol dirinya melakukan strategi pemecahan masalah yang dihadapi ditempat kerja agar dapat mengurangi tingkat burnout yang dialami dan meningkatkan kinerja dalam memberikan pelayanan kesehatan kepada pasien (Sulistyowati, 2007).

Hasil penelitian ini juga di dapatkan beberapa responden memiliki burnout yang tinggi, tetapi self efficacynya rendah sebanyak 4 orang $(7,8 \%)$. Menurut Harnida (2015) bahwa Self Efficacy tidak berpengaruh terhadap terjadinya burnout. Seperti yang di ketahui bahwa beban kerja perawat secara fisik tidak terlalu berat, namun secara psikis perawat memiliki beban yang cukup berat, keitka beban kerja yang ada terlalu berat tidak diimbangi dengan keyakinan (Self Effycacy) yang cukup untuk melaksanakan tugas, maka yang muncul ialah perasaan tidak berdaya karena beban yang terlalu berat. Hal ini juga akan memacu munculnya burnout pada perawat (Harnida, 2015).

Self efficacy dengan burnout pada perawat menunjukan bahwa self efficacy menjadi salah satu faktor yang menyebabkan terjadinya burnout. Faktor lain yang dapat menyebabkan burnout adalah faktor lingkungan seperti kondisi kerja. Dukungan sosial dari lingkungan tempat kerja, teman kerja, atasan dan keluarga terbukti menjadi faktor yang mempengaruhi tinggi rendahnya burnout (Natsir, dkk, 2015).

\section{SIMPULAN}

Penelitian ini mayoritas perawat memiliki Burnout yang tinggi dan memiliki Self Efficacy yang tinggi. Dalam penelitian ini, terdapat hubungan yang signifikan antara Burnout dengan Self Efficacy pada perawat di ruang rawat inap

\section{DAFTAR PUSTAKA}

Al-Turki, H.A.et al. (2010). Burnout Syndrome Among Multinational
Nurses Working in Saudi Arabia. Saudi Med Journal, 31(3): 313-316.

Dora, M. T. danKadir, H. A. (2014). Mengurus Stres. Jakarta: PTS Proffesional Publishing

Ferianto, K., Ahsan., Rini, I., S. (2016). Analisis faktor-faktor yang mempengaruhi self efficacy perawat dalam melaksanakan resusitasi pada pasien henti jantung. Prodi Magister Keperawatan Fakultas Kedokteran Universitas Brawijaya

Harnida, H. (2015). Hubungan efikasi diri dan dukungan sosial dengan burnout pada perawat. Fakultas ilmu kesehatan universitas merdeka Surabaya

Huber, D.L., 2006.Leadership and Nursing Care Management. Philadelpia.WB SounderMoreira, et al. (2009).Prevalence of Burnout Syndrome in Nursing Staff In A Large Hospital in South of Brazil. Medline Journal, 25(7):1559-68

Juniartha, I., G., N., Candra, I., P., R. (2013). Hubungan tingkat self efficacy dengan tingkat burnout pada perawat di igd rsud badung mangusada. Prodi Ilmu Keperawatan Fakultas Kedokteran Universitas Udayana

Natsir, M., Hartiti, T., Sulisno, M. (2015). Hubungan antara self efficacy dan stres kerja dengan burnout pada perawat dalam melakukan asuhan keperawatan pada rs pemerintahan di kabupaten semarang. Jurusan Keperawatan Universitas Diponegoro Semarang

Notoadmojo. (2010). Metodologi Penelitian Kesehatan. Jakarta : PT. Rineka Cipta.

Pajares. (2002). Self-efficacy beliefs in academic contexts: An outline. [Online] Available: http://www.emory.edu/EDUCATIO N/mfp/efftalk.html

Pamungkas, D., N., P. (2018). Hubungan antara self efficacy dengan burnout 
terhadap perawat rumah sakit jiwa daerah surakarta. Prodi Psikologi Fakultas Psikologi Universitas Muhammadiyah Surakarta

Pangastiti, N.K. (2011). Analisis Pengaruh Dukungan Sosial Keluarga Terhadap Burnout Pada Perawat Kesehatan Di Rumah Sakit Jiwa. Semarang Fakultas Ekonomi Universitas Diponegoro.

Perry, A.G.\& Potter, P.A. (2005).Buku Ajar Fundamental Keperawatan: Konsep, Proses, dan Praktik (Volume 2) (Edisi 4).Jakarta: EGC

Rachmawati, E. (2008). 50,9 Persen Perawat Alami Stress.

Kerja.(Online)

(http://www.kompas.com/kesehatan / 50,9 Persen Perawat Alami Stress Kerja-Kompas Cyber Media)

Robbins, S., P., Judge, T., A. (2008). Perilaku Organisasi. Jakarta: Salemba

Simamora, R., H. (2008). Pengaruh pelaksanaan rotasi kerja terhadap kinerja perawat di rumah sakit umum daerah dr. h. Koesnadi bondowoso. Jurnal administrasi kesehatan, vol 4

Srihandayani, I., S. (2016). Hubungan antara self efficacy dengan kinerja perawat dalam melaksanakan asuhan keperawatan di igd dan icuiccu rsud Dr. soehadi prijonegoro sragen. Prodi Keperawatan Stikes Kusuma Husada Surakarta

Sulistyowati, Priyatin. (2007). Hubungan antara burnout dengan self efficacy pada perawat di ruang rawat inap rsud prof. Dr magono soekarjo purwekerto. Akper Yakpermas, Banyumas

Susanti, E., N. (2013). Hubungan karakteristik perawat dengan motivasi perawat dalam pemenuhan kebutuhan kebersihan diri pasien di ruangan rawat inap rsu dr. $h$. Koesnadi bondowoso. Prodi Ilmu Keperawatan Universitas Jember 